\title{
Viagens pelo campo virtual: aprendendo além dos muros da sala de aula ${ }^{1}$
}

Jeff Scott

Nipissing University

\section{Resumo}

Este artigo fornece uma visão geral acerca de uma abordagem holística destinada a envolver os alunos em processos de leitura e escrita, enquanto envolvidos com um tema científico. Recentes avanços no campo da tecnologia e do acesso à Internet abriram uma infinidade de recursos nunca antes disponíveis para professores e alunos. Muitos destes, incluindo viagens de campo virtual, podem ser usados para estimular o interesse e motivar os alunos a selecionarem os seus próprios tópicos de interesse e orientarem pesquisas, leituras e aprendizagens (Scott, 2007). Este artigo apresenta um relato sobre a exploração e o uso de viagens de campo virtuais como uma forma de envolver os alunos em atividades de pesquisa, escrita e compartilhamento de conhecimentos, em desenvolvimento, sobre o ciclo de vida de águias. 0 local de nidificação das águias em Decorah, lowa, forneceu o local para a viagem de campo virtual que está sendo relatado.

Palavras-chave: Viagem de campo virtual. Leitura. Escrita.

1. Tradução: Gilberto Lacerda dos Santos. 


\section{Virtual Field Trips: learning beyond the Classroom Walls}

This paper provides an overview of a holistic approach to engaging students in the reading and writing processes while engaged with a science topic. Recent advances in technology and internet access have opened up a multitude of resources never before available to teachers and students. Many of these, including Virtual Field Trips can be used to stimulate interest and motivate students to select their own topics of interest and self direct their own research, reading, and learning (Scott, 2007). This paper presents the exploration and use of Virtual Field Trips as a means of engaging students in researching, writing, and sharing with others their developing knowledge on the lifecycle of an eagle. The nesting site of the eagles in Decorah, lowa provides the location for the Virtual Field Trip being reported on.

Keywords: Virtual Field Trip. Reading. Writing.

\section{Viajes por el campo virtual: aprendiendo más allá de los muros del aula}

Este artículo ofrece una visión general acerca de un abordaje holístico destinado a involucrar alunos en procesos de lectura y escritura, mientras estaban implicados en un tema científico. Recientes avances en el campo tecnológico y de acceso a Internet abrieron una infinidad de recursos nunca antes disponibles para professores $y$ alumnos. Muchos de estos avances, incluyendo viajes de campo virtual, pueden ser usados para estimular el interés y motivar a los alumnos para selecionar sus propios tópicos de interés y orientar investigaciones, lecturas y aprendizajes (Scott, 2007). Este artículo presenta un relato sobre la explotación y uso de viajes de campo virtuales como forma de involucrar a los alunos en actividades de investigación, escritura e intercambio de sus conocimientos en el desarrollo del ciclo de vida de águilas. El local donde nidifican las águilas es en Decorah, lowa, ofreciendo el local para el viaje de campo virtual que está siendo relatado.

Palabras clave: Viaje de campo virtual. Lectura. Escritura. 


\section{Introdução}

Em Ontário/Canadá, o Ministério da Educação impôs um currículo padronizado, que tem foco predominante na leitura e na escrita. Para se ter sucesso no sistema escolar de Ontário, é necessário tornar-se proficiente em leitura e escrita desde cedo, mas, infelizmente, nem todos os alunos conseguem desenvolver habilidades básicas de alfabetização no mesmo ritmo ou pelas mesmas experiências. Fundamentado na suposição de que a leitura e a escrita são componentes integrantes e inseparáveis do conceito mais amplo de alfabetização, que envolve a audição, a fala, a leitura, a escrita, a visualização e a representação (Parr; Campbell, 2006), este artigo fornece uma visão geral de uma abordagem holística para envolver os alunos em processos de leitura e escrita utilizando o tema da biodiversidade. Recentes avanços na tecnologia e o aumento do acesso à Internet abriram uma infinidade de recursos nunca antes disponíveis para professores e alunos. Muitos destes recursos, incluindo viagens de campo virtual, podem ser usados para estimular o interesse e motivar os alunos a envolverem-se com a tecnologia a fim de orientarem sua própria pesquisa, o que pode ser usado como uma ponte para fomentar atividades de leitura e de escrita (Scott, 2007). Passeios virtuais também podem fornecer uma oportunidade para os alunos verem, ouvirem e, possivelmente, interagirem com especialistas no assunto de interesse dos alunos (Zanetis, 2010).

Esta pesquisa procurou explorar como seis professores do ensino fundamental usam as viagens virtuais para envolver seus alunos em uma variedade de áreas curriculares, incluindo a ciência e a tecnologia, estudos sociais, música e artes, proporcionando verdadeiras e significativas experiências de leitura e de escrita. Além disso, a pesquisa também investigou como os alunos utilizam a tecnologia tanto em hardware quanto em software, tais como SMART Ideas, PowerPoint e Dragons Naturally Speaking como suportes para o desenvolvimento de habilidades, como resultado da utilização de viagens de campo virtuais.

A pesquisa foi realizada em 2010 no contexto de uma rede de ensino do nordeste da província de Ontário. Os seis professores que participaram do estudo, todos atuando no $5^{\circ}$ ou no $6^{\circ}$ ano, eram de diferentes escolas, localizadas dentro de uma faixa de vinte quilômetros de um centro urbano com uma população de cerca de cinquenta mil pessoas. As seis escolas, relativamente pequenas em termos de alunos e professores, tinham menos de trezentos alunos e menos de quinze professores. Cada professor, com apoio externo, teve a oportunidade de pesquisar, discutir e implementar as viagens de campo virtuais em sua rotina de ensino. 


\section{Viagem no campo virtual}

A viagem de campo virtual pode ser considerada uma atividade extraclasse, em que os participantes visitam um local virtualmente e participam de uma atividade sem ter que deixar a escola (Scott, 2007). Com o avanço da tecnologia, os professores podem agora organizar excursões multimídia para visitar locais de difícil acesso, sem que seus alunos saiam da sala de aula. Além disso, viagens de campo virtuais podem proporcionar aos alunos uma oportunidade de visualizar sua própria leitura do material do site, participar de atividades durante a criação e o uso de ferramentas visuais destinadas a organizar conteúdos, construir significados e analisar e compreender seus procedimentos (Standen, 2005; Strickland, Ganske, Monroe, 2006). Diante disso, esperava-se que estas viagens de campo virtuais pudessem tornar-se meios eficazes para atrair os alunos, motivá-los ou envolvê-los em atividades de leitura e escrita durante o desenvolvimento de habilidades e conhecimentos e da consciência da importância da ciência em suas vidas .

Um revisão de literatura identifica vários argumentos de apoio à utilização de viagens de campo virtuais. Estes incluem: aumento da concentração do aluno em situações em que eles controlam o ritmo das apresentações, o cronograma das viagens e os pré-requisitos; uso de múltiplos meios de aprendizagem nos quais uma variedade de estímulos (áudio, vídeo, texto) pode beneficiar uma ampla gama de alunos com diferentes estilos de aprendizagem; independência geográfica, tendo em vista que os alunos podem visitar sites em qualquer lugar do mundo sem sair da escola; facilidade de uso, na medida em que a navegação na web está tornando-se cada vez mais fácil (Risinger, 2010). Além disso, fatores como clima, ambientes inseguros ou problemas logísticos associados às viagens (custos, reserva de locais em eventos, obtenção de permissões e licenças) são eliminados (Klemm; Tuthill, 2002). É também importante salientar que viagens de campo virtuais podem oferecer oportunidades de aprendizagem antes inatingíveis; recursos, experiências e conhecimentos de outros espaços, bem como o acesso a imagens e sons de lugares distantes que podem agora ser levados para a sala de aula (Scott, 2007; Zanetis, 2010). Feldman (2002) afirma que os alunos podem aprender sobre diferentes culturas, apreciar a diversidade e ampliar seu conhecimento: "Além disso, imagens digitais acessadas pela internet permitem aos alunos registrarem e documentarem as suas experiências. Estas imagens incentivam a reflexão e fornecem um trampolim para a discussão e para a escrita" (Feldman, 2002, p. 2).

Uma viagem de campo virtual bem escolhida pode conter muitos dos atributos encontrados em um software educativo de qualidade para a promoção de habilidades de leitura e escrita. Esses atributos incluem recursos audiovisuais de alta qualidade, 
mecanismos interativos, múltiplos meios de representação, escolha, espaço e sensação de controle (Strickland; Ganske; Monroe, 2006). Além disso, a pesquisa que incidiu sobre os estudantes, utilizando a instrução assistida por computador, relata maior motivação para ler, desenvolvimento de uma atitude positiva em relação à leitura, aumento da compreensão, maior fluência e melhoria da ortografia (Standen, 2005; Underwood, 2000).

A utilização de passeios virtuais em conjunto com a visão construtivista da aprendizagem permite aos estudantes oportunidades de se aprofundarem em áreas de interesse pessoal, as quais lhes fornecem mais motivação para explorarem temas sobre os quais têm curiosidade. Esta abordagem aproveita o interesse dos alunos para

criar estruturas mentais que organizam e sintetizam as informações e experiências que o indivíduo encontra no mundo. Tecnologias de informação e comunicação, como a Internet, dão suporte a esta abordagem de ensinar e de aprender, o que estimula a aprendizagem em contextos reais, a colaboração e apoios externos, o uso de material de múltiplas fontes primárias e recursos, como livros didáticos (Fulton, 1997, p. 28 ).

Além disso, oferecer opção para os estudantes é fator comprovado de motivação (Risinger, 2010; Veto, 2006). Oferecer uma variedade de viagens de campo virtual para os alunos, para que eles possam facilmente selecionar um tema que lhes interessa, reduz 0 risco de que se desconectem com o tema de estudo, achando-o desinteressante (Veto, 2006).

\section{Procedimentos metodológicos}

Nesta pesquisa, foi empregada uma abordagem de estudo de caso instrumental (Bogdan; Biklen, 2003; Creswell, 1998; Stake apud Denzin; Lincoln, 2005), com o objetivo de fornecer aos professores um processo para melhorar as suas próprias práticas de ensino e lançar luz sobre os possíveis benefícios da utilização de passeios virtuais como estratégia para o desenvolvimento da leitura e da escrita. Seis casos foram examinados. 0 estudo qualitativo foi realizado durante um período de seis meses no ano de 2010 , utilizando um modelo de pesquisa-ação (McTaggart, 1991; Mertler, 2006; Pedretti, 1996, 1994), a qual inclui "um ciclo repetitivo de planejar, agir, observar/avaliar e refletir em um ambiente de apoio mútuo" (Hodson, 2001, p. 43) para melhorar a qualidade do próprio programa. Os professores participantes do estudo utilizaram uma variedade de viagens de campo virtuais em diversas áreas curriculares para atender as expectativas ou os resultados específicos, tal como estabelecido pelo Ministério da Educação de Ontário. 
Os participantes da pesquisa foram reunidos aproximadamente a cada duas semanas (10 sessões) por aproximadamente 2 horas, em reuniões organizadas e conduzidas da seguinte forma:

1. Uma revisão das reuniões anteriores com discussão de temas-chave, a fim de que os pesquisadores pudessem esclarecer questões e garantir a precisão da discussão da sessão anterior. Este processo permitiu aos pesquisadores analisar ainda mais suas percepções acerca da investigação.

2. Uma discussão sobre o material fornecido na reunião anterior para leitura.

3. A revisão do que cada professor trabalhou individualmente com seus alunos, na qual os professores identificam os eventos bem-sucedidos e os malsucedidos, enquanto os alunos estavam envolvidos com as viagens de campo virtuais.

4. A distribuição de um artigo a ser lido para a próxima sessão. Este artigo era fornecido para promover a discussão e fornecer informações relevantes em áreas como pesquisa-ação, como um processo de melhoria para o ensino e a utilização de viagens de campo virtuais. Cada professor era também incentivado a trazer recursos considerados interessantes para outros membros do grupo.

5. A dedicação a um tempo de interação entre os professores. Nos encontros, também era dedicado um tempo para interação, durante os quais vários sites destinados às viagens virtuais eram visitados. Estas sessões permitiam a avaliação dos diversos sites disponíveis, antes de estes serem propostos aos alunos.

6. A elaboração, por parte de cada professor, de diretrizes para eles próprios e para seus alunos, para as próximas duas semanas, o que incentivava a apropriação da pesquisa como algo pessoal e relevante para cada participante (Bogdan; Biklen, 2003).

Cada sessão foi gravada, o que garantiu precisão nos dados. Após cada reunião ou entrevista, a gravação foi transcrita, o que ajudou na identificação de temas emergentes, bem como na definição de direcionamentos para futuras reuniões. Cada professor utilizou uma variedade de viagens de campo virtuais. Em alguns casos, os estudantes visitaram o site apenas uma vez, enquanto em outros casos os alunos puderam visitar o site várias vezes ao longo do tempo permitido; a média de visitas a cada local virtual foi de oito a dez vezes. Cinco dos seis professores participantes integraram passeios virtuais em seus programas de ciências. Além disso, dois participantes incluíram passeios virtuais em seu programa de artes, enquanto um professor integrou uma viagem de campo virtual em seu currículo de música. Além do período de pesquisa, viagens virtuais levaram os participantes a museus, onde foram estudadas as primeiras expedições à Antártida, para investigarem o pinguim-imperador; ao Campsite $24^{2}$, para

2. 0 Campsite 24 é site destinado a estudantes e professores com informações sobre parques de Ontário e áreas protegidas. Para maiores informações cf. http://www.campsite24.ca/ <acesso em 20/09/2011>. 
explorarem as plantas, animais selvagens e proteção ambiental; e à China, para aprenderem sobre uma escola mantida pelo grupo Free the Children. Outras viagens levaram os participantes para um estúdio de gravação, onde músicas foram compostas e gravadas; para uma estação de geração de energia elétrica, onde os alunos investigaram como a água foi utilizada para produzir eletricidade; e ao espaço, para experimentar como astronautas lidam com a falta de gravidade.

Esta pesquisa primeiramente se dissocia do paradigma naturalista, permitindo que os temas e as conclusões surjam das situações particulares em estudo (Lincoln; Guba, 2000). Múltiplas técnicas foram utilizadas para triangular os dados, incluindo entrevistas gravadas e discussões em grupo, anotações em diários pessoais, notas de campo coletadas durante as visitas de salas de aula e amostras de trabalho dos alunos. Além disso, uma pesquisa descritiva, em três partes, foi utilizada para obter os dados demográficos e características (ou seja, atitudes, habilidades e conhecimentos) dos professores participantes. A primeira parte foi composta de perguntas de natureza demográfica lou seja, gênero e como cada participante utiliza o computador). A segunda parte sondou os sentimentos dos professores sobre computadores e seus usos. A terceira parte examinou as percepções dos professores acerca de sua competência computacional.

A entrevista pode ser utilizada para coletar dados descritos pelos próprios sujeitos (Bogdan; Biklen, 2003). Nesta pesquisa, foram realizadas entrevistas antes, durante e depois com cada um dos seis participantes, totalizando 18 entrevistas e aproximadamente 54 horas de gravação. Expectativas pessoais do projeto, uso atual e passado da tecnologia instrucional, relações com leitura e escrita, bem como nível de conforto pessoal acerca da tecnologia foram discutidos na entrevista inicial. Nas entrevistas de percurso foram analisados os temas de trabalho de cada professor, a fim de garantir uma recriação exata dos acontecimentos. Na entrevista final, cada professor compartilhou suas percepções pessoais e descobertas ao longo do período de investigação. Informações obtidas incluíam situações bem-sucedidas e possibilidades de melhoria de uso dos passeios virtuais e sobre como elas podem auxiliar os alunos a desenvolverem competência de leitura e escrita. Também, a integração da tecnologia como resultado da utilização das viagens de campo virtuais, bem como o crescimento pessoal resultante da participação neste projeto de pesquisa foram compartilhados.

Um diário pessoal foi fornecido para cada professor, para registro de seus pensamentos sobre como eles exploraram o tema de pesquisa, questões ou preocupações que eles tinham, descobertas interessantes e pensamentos acerca de seus alunos. Pesquisas indicam que a manutenção de um diário permite aos participantes que reflitam sobre sua aprendizagem e proporcionam um "registro descritivo e reflexivo dos acontecimentos, e das respostas pessoais deles" (Connelly; Clandinin, 1999, p. 136). 
Cada professor e seus alunos foram observados quando se encontravam em viagem de campo virtual em pelo menos uma ocasião. Foi durante essas visitas que o pesquisador foi capaz de observar cada cultura escolar e práticas de sala de aula. Como Bogdan e Biklen (2003, p. 112) constatam, o objetivo de reunir notas de campo descritivo "é capturar a fatia da vida" no ambiente em que se está trabalhando. Áreas de interesse investigadas durante as visitas incluíram o cenário no qual a observação ocorreu, o componente de instrução da aula, o interesse dos alunos na aula e de aplicação da viagem de campo virtual, as interações entre professor e alunos, alunos e alunos, e alunos e tecnologia. Discussões informais foram realizadas com cada professor e seus alunos durante todo o período de observação. Notas de campo foram coletadas e posteriormente transcritas.

Vários professores forneceram amostras de trabalhos produzidos por seus alunos após a realização de viagens de campo virtuais. Trabalhos dos alunos foram coletados para informar os professores de suas práticas pessoais e fornecer feedback sobre 0 que estava acontecendo em termos de aprendizagem. A maioria dos professores participantes informou que não havia um componente escrito decorrente da viagem de campo virtual, mas que seus alunos eram induzidos a elaborarem apresentações eletrônicas ou outros modos de representação, como histórias em quadrinhos.

\section{Resultados da pesquisa}

Como indicado anteriormente, os professores participantes utilizaram uma variedade de locais para envolver seus alunos. A viagem de campo virtual para Decorah, lowa, na primavera de 2010, e a maneira em que esta viagem foi utilizada pelos professores são descritos a seguir.

A viagem de campo virtual preferida pelos professores e alunos do projeto de pesquisa foi aquela intitulada "O Ninho da Águia Careca e seus Ovos", localizado em Decorah, lowa (www.ustream.tv/channel/eagle-cam). Este link dava acesso a uma cobertura ao vivo das águias em um ninho, através de uma webcam, colocada a fim de permitir a observação de um par de águias, simultaneamente, incubando três ovos; a cobertura foi feita durante 24 horas por dia, com o auxílio de uma câmera infravermelha para a visualização noturna. Os ovos eclodiram no início de abril de 2010. As águias adultas novamente utilizaram este local de nidificação na primavera de 2011.

Vários professores indicaram que utilizaram esse site muito informalmente, por exemplo, como um protetor de tela no computador da sala de aula, e haviam deixado - local aberto mesmo se os alunos não estavam utilizando os computadores da sala de aula para outros fins. Outros professores fizeram com que seus estudantes partici- 
passem desta visita virtual duas ou três vezes por semana, em horários agendados no laboratório de informática. Três professores criaram um diário em que os alunos deveriam registrar suas observações a respeito das águias, o que foi um meio eficaz para os alunos desenvolverem habilidades de escrita informativa. Os estudantes puderam observar, discutir e, em seguida, registrar as observações e escrever inferências com base em suas observações (Akerson; Young, 2005).

Deanna, uma das professores entre os participantes, indicou que havia vários escritores relutantes em sua classe. Ela informou que a viagem de campo virtual dedicada às águias chamou a atenção desses alunos e eles pareciam mais interessados em escrever sobre o que estavam vendo. Nem todos os estudantes se sentiram imediatamente confortáveis com a escritura no diário do grupo, mas todos escreviam em seus diários pessoais, como indicado pelo seguinte depoimento:

Tenho vários meninos na minha classe que consideram que escrever é um verdadeiro desafio. Em alguns casos, eles têm medo de estarem errados com a sua ortografia ou o uso de pontuação, o que faz com que eles geralmente escrevam muito pouco. No que diz respeito ao site da águia, três dos rapazes dedicaram uma seção de seu diário pessoal para este tema e escreveram várias notas sobre o mesmo. Embora as notas fossem geralmente limitadas a algumas frases, um rapaz realmente escreveu vários parágrafos, duas ou três vezes por semana, descrevendo as águias, seus ninhos, sons, e assim por diante. Na verdade, ele completou um projeto sobre águias, o qual foi apresentado a seus colegas de classe. Fiquei muito impressionada... (professora Deanne).

Jonathan, outro professor, indicou que seus alunos escreveram, no diário coletivo, desde uma linha a vários parágrafos, fornecendo detalhes sobre as observações das ações dos pássaros, a colocação dos ovos e os sons da natureza em torno do ninho: "Foi interessante ver os escritores mais relutantes colocarem seus pensamentos no papel e não se preocuparem com ortografia, pontuação ou gramática", afirmou Jonathan. Um comentário escrito descreveu o som de um cortador de grama nos arredores das águias, o que levou o aluno a se preocupar com o impacto dos seres humanos sobre o desenvolvimento das águias após o nascimento. Isto levou a uma discussão e a uma pesquisa fora da sala de aula por parte do aluno autor desse questionamento. Os resultados da investigação foram compartilhadas com seus colegas no dia seguinte.

Matt, outro professor, relatou que utilizou o mencionado site enquanto estudava o tema da biodiversidade em seu programa de ciências no $6^{\circ}$ ano. Ele constatou que alguns de seus alunos que geralmente não demonstravam muito interesse por ciências 
tiveram um interesse real pelas águias. Segundo o professor, o comportamento das águias gerou muita curiosidade entre os alunos, do que decorreu um maior envolvimento com o conteúdo da unidade de ciências:

À medida que os alunos tornaram-se mais envolvidos com as águias, parecia que a sua capacidade de observação tornava-se mais desenvolvida e eles foram apresentar e compartilhar os pequenos detalhes que pareciam escapar de seus colegas. Além disso, eles começaram a elaborar hipóteses bem formuladas sobre as ações das águias e os seus filhotes. Foi gratificante ver que o interesse pelas águias foi levado para a unidade de ciência e era bastante comum ver o estudante "desinteressado" passar a relacionarse com o tema a partir do interesse pelas águias. As conexões entre as duas áreas foi incrível... (professor Matt).

Jonathan declarou que este uso informal da viagem de campo virtual representou um fator motivador para seus alunos:

Os estudantes amaram a viagem virtual sobre as águias. Todas as manhãs, muitos dos alunos entraram na sala de aula e, sem sequer tirar seus casacos ou arrumar suas coisas, vinham ver o que estava acontecendo com as águias.

Quando um membro do grupo de pesquisa perguntou a Jonathan sobre a utilização de matérias do jornal como parte de seu programa de linguagem, Jonathan respondeu:

Pudemos introduzir e reforçar a escrita científica durante boa parte do tempo. Fomos capazes de discutir o uso de palavras descritivas, a importância de escrever notas de campo precisas e o valor da percepção individual. Os alunos foram capazes de fazer conexões entre o que eles estavam vendo no monitor e o que estava acontecendo ao seu redor na escola. Parecia haver mais interesse nas aves de nossa área, como resultado do trabalho com as águias... (professor Jonathan).

O site visitado não só forneceu informações gerais e conhecimentos sobre o cotidiano das águias, a preparação do ninho para os bebês e os cuidados com os filhotes; propiciou também um diálogo rico e significativo, que ajudou a consolidar as aprendizagens decorrentes da viagem de campo virtual. Em muitos casos, essa "conversa fundamentada", como sugerido por Kilbourn (2000, p. 139), gerava ideias que inspirav am os alunos em seus escritos pessoais. Kilbourn chamou esse tipo de conversa de "fundamentada" porque envolve "inquérito genuíno" (Kilbourn, 2000, p. 115), em que o 
professor e os alunos são incentivados a participarem de uma conversa e tornam-se intelectualmente envolvidos na interpretação do assunto. Quando envolvidos em um diálogo desta natureza, o professor e os alunos são convidados a interpretarem os fatos de forma mais consistente. É através destes meios que interpretações alternativas são criadas. Como Kilbourn (2000, p. 139) afirma, "a conversa fundamentada é sobre o processo e é o assunto que fornece a substância". De acordo com os professores participantes, todos os alunos se beneficiaram da oportunidade de participar de conversas fundamentadas. Vários professores afirmaram que vários alunos, apesar de relutantes, elaboravam comentários perspicazes, o que lhes incentivava a seguir na viagem virtual. Estes comentários eram geralmente elaborados de forma escrita, seja em um diário pessoal, seja em um projeto de pesquisa em que estavam trabalhando. Além disso, esses "escritores" pareciam mais interessados em localizar informações, tanto on-line como em livros e revistas. Percebeu-se também que o fornecimento de uma oportunidade para uma conversa após a viagem de campo virtual era importante para trazer clareza à experiência, permitindo que detalhes fossem compartilhados entre os indivíduos do grupo.

A professora Jessica relatou que realizou cinco visitas consecutivas para o ninho das águias e que provocou uma discussão após cada visita, além de uma sessão de teatro de improviso, quando os alunos encenaram situações decorrentes do que tinham visto durante as visitas. Ela indicou que quatro ou cinco de seus alunos que em geral rejeitavam a ideia de escrever mais de duas ou três frases estavam muito ansiosos para escrever. Utilizando Dragons Naturally Speaking, seus alunos foram capazes de afirmar as suas ideias oralmente, enquanto o software provia a digitação automática do texto no computador: "As peças produzidas pelos alunos foram muito detalhadas, emocionais e sofisticadas. Os alunos nunca tinham produzido obras dessa qualidade e todos ficaram impressionados com a qualidade", afirmou Jessica.

Passeios virtuais, como ao local de nidificação da águia de Decorah, lowa, parecem estar ganhando em popularidade. 0 local de assentamento a partir de 2011 está agora bem documentado na Internet com clipes de vídeo on-line incluindo as numerosas eclosões, o processo de alimentação e a criação das jovens águias. A popularidade desta forma de viagem de campo virtual está crescendo, tendo em vista que, em 2011 , mais de cem milhões de pessoas estiveram em sintonia com as atividades das águias ao longo de vários meses, desde a colocação dos ovos para a incubação e criação das águias, até a sua saída do ninho (Empson, 2011). Atualmente, muitos passeios virtuais semelhantes existem, e oferecem a oportunidade de ver o nascimento de animais, tanto em liberdade quanto em cativeiro (em zoológicos, por exemplo). 


\section{Considerações finais}

Os professores envolvidos nesta pesquisa, puderam constatar o valor da utilização das viagens de campo virtuais para fomentarem o interesse pela leitura e escrita dos estudantes, ao mesmo tempo em que estão envolvidos com investigações relacionadas às ciências naturais. Seus alunos demonstraram maior motivação para elaborar relatos tanto em diários coletivos quanto em diários pessoais e se mostraram mais interessados em completar uma variedade de projetos de pesquisa em profundidade, devido a um aumento da motivação, estimulada pelas viagens de campo virtuais. Vários professores indicaram que a implementação de passeios virtuais proporcionou oportunidades para integrar a tecnologia em suas salas de aula, oferecendo a seus alunos um sentido de objetividade em suas aprendizagens. Os alunos foram capazes de utilizar vários softwares, tais como SMART Ideas, PowerPoint e Dragons Naturally Speaking para organizar e publicar escritos pessoais. A tecnologia foi utilizada de forma mais ampla, e, neste sentido, o estudo oferece uma contribuição para a nossa compreensão teórica das viagens de campo virtuais enquanto elemento motivador da leitura e da escrita, através da utilização da tecnologia.

Este estudo também lança luz sobre a importância de envolver os alunos propositalmente em uma viagem de campo virtual, e não apenas visitar sites com pouca expectativa. A tecnologia permite-nos realizar viagens em praticamente qualquer lugar no mundo, desde os pólos da terra, as florestas tropicais da Amazônia, até as planícies, o interior de um carro novo, o quarto de um hotel em que você poderia se hospedar em um dia. Muitas vezes, essas visitas são mais úteis para propiciar a coleta de informações do que para gerar conhecimento mais aprofundado ou promover o desenvolvimento de competências. Vários professores indicaram que, quando os seus alunos estavam fazendo uma viagem de campo virtual de forma aleatória, com pouca ou nenhuma expectativa, eles não se lembravam de fatos específicos, em contraste com o que acontecia no caso de viagens propositais.

Como educadores podemos capitalizar o fato de que os alunos aprendem de forma diferente e têm diferentes interesses e capacidades e habilidades, oferecendo um vasto leque de atividades/estratégias que podem envolvê-los em atividades de aprendizagem. As viagens de campo virtuais podem ser usadas como ganchos para motivar e envolver os alunos, incluindo o leitor e o escritor relutantes. É importante mencionar que nem todos os passeios virtuais motivam a todos os alunos, mas, se formos capazes de usar essa tecnologia para captar o interesse e regenerar a motivação mesmo de poucos alunos, isto certamente fará uma grande diferença em suas vidas individuais, com resultados para toda a vida. 


\section{Referências}

AKERSON, Valarie; YOUNG, Terrell. Science the "write" way. Science \& Children. Arlington VA, v. 43, n. 3, p. 38-41, nov./dez. 2005.

BOGDAN, Robert; BIKLEN, Sari. Qualitative research for education: An introduction to theories and methods (4 ${ }^{\mathrm{a}}$ Ed.). Toronto: Allyn and Bacon, 2003.

CRESWELL, John. Qualitative inquiry and research design: Choosing among five traditions. Thousand Oaks: Sage Publications, 1998.

EMPSON, Rip. Nearing 100 million views, decorah eagles become the most watched live stream ever. (n.d.). Disponível em <http://techcrunch.com/2011/05/12/nearing-100-million-views-decorah-eaglesbecome-the-most-watched-live-stream-ever/>. Acesso em: 15 setembro de 2011.

FELDMAN, Dara. Technology and early literacy: A recipe for success. 2002. Disponível em $<w w w . m o n t g o m e r y s c h o o l s m d . o r g / c u r r i c u l u m / l i t t l e k i d s / r e s o u r c e s / r e c i p e . p d f>$. Acesso em: 15 setembro de 2011.

FULTON, Kathleen. Learning in a digital age: Insights into the issues. Technological Horizons In Education. Irvine, n. 25, p.14-41, 1998.

GUTHRIE, Larry F.; RICHARDSON, Susan. Language arts: Computer literacy in the primary grades. Educational Leadership. Alexandria, v. 53, n. 2, p. 14-17, 1995.

GARDNER, Howard. Multiple intelligences: New horizons. New York: Basic Books, 2006.

HODSON, Derek. Science curriculum development: Lessons from the past. In: DEREK. Hodson; BENCZE, John Lawrence; PEDRETTI, Erminia; NYHOF-YOUNG, Joyce (Eds.) Changing science education through action research: Some experiences from the field. Toronto: Imperial Oil Centre for Studies in Science, Mathematics and Technology Education; Ontario Institute for Studies in Education, University of Toronto, 2001, p. 25-43.

KILBOURN, Brent. For the love of teaching. London: The Althouse Press, 2000.

KLEMM, Barbara; TUTHILL, Gail. Virtual field trips: Best practices. International Journal of Instructional Media. Tolland, v. 30, n. 2, p. 177-193, 2002.

LINCOLN, Yvonna; GUBA, Egon. Paradigmatic Controversies, Contradictions, and Emerging Confluences. In: DENZIN, Norman; LINCOLN, Yvonna (Eds.). Handbook of Qualitative Research. Thousand Oaks: Sage, 2000, p.163-188.

MERTLER, Craig. Action research: Teachers as researchers in the classroom. Thousand Oaks: Sage Publications, 2006.

ONTARIO MINISTRY OF EDUCATION AND TRAINING. The Ontario curriculum, Grades 1-8: social studies. Toronto, On: Queen's Printer for Ontario, 1998.

PARR, Michann; CAMPBELL, Terry. Teaching the language arts. Mississauga, On: John Wiley \& Sons, Ltd, 2012.

PEDRETTI, Erminia. Facilitating action research in science, technology and society (STS) education: an experience in reflective practice. Educational Action Research. Routledge, v. 9, n. 3, p. 307-327, 1996. 
PEDRETTI, Erminia. Action research in science-technology-society education: The road less traveled (Unpublished doctoral thesis). Ontario Institute for Studies in Education, University of Toronto, Toronto, Canada, 1994.

RISINGER, C. Frederick. Using online field trips and tours in social studies. Social Education, 74(3), 2010. 137-138.

SCOTT, Jeff. Exploring the use of virtual field trips with elementary school teachers: A collaborative action research approach (Unpublished doctoral thesis). Ontario Institute for Studies in Education, University of Toronto, Toronto, Canada, 2007.

STAKE, Robert. E. Case Studies. In: DENZIN, Norman; LINCOLN, Yvonna. (Eds.), Handbook of qualitative research (2nd Ed). London: Sage Publishing, 2005, p. 236-247.

STANDEN, Andrew. Grounded. Edutopia, October, 2005, p. 34-39.

STRICKLAND, Dorothy S.; GANSKE, Kathy; MONROE, Joanne K. Supporting struggling readers and writers: Strategies for classroom intervention. Portland: Stenhouse Publishing, 2006.

UNDERWOOD, Jean. A comparison of two types or computer support for reading development. Journal of Research in Reading. Coventry, v. 23, n. 2, p.136-148, 2000.

VETO, Dori. Motivating reluctant adolescent readers. The School Administrator. Alexandria, v. 63, n. 4, p. 31-34, 2006.

ZANETIS, Jan. The beginner's guide to interactive virtual field trips. Learning \& Leading with Technology. Eugene, v. 37, n. 6, p. 20-24, 2010.

Recebido em outubro de 2011.

Aprovado em janeiro de 2012.

Jeff Scott, phd em Educação (Currículo) obtido no Ontario Institute for Studies in Education, University of Toronto. É professor da Schulich School of Education na Nipissing University - North Bay, Ontario, Canadá. Publicações recentes: Pledging for sustainability: One act at a time (The International Journal of Environmental, Cultural, Economic and Social Sustainability, 2011); Modeling in the classroom: What approaches are effective to improve students' writing? (co-autoria com Nancy Maynes. In Education, vol.17, n.1, 2011). E-mail: jeffsanipissingu.ca

Tradutor: Gilberto Lacerda dos Santos. Professor Associado do Departametno de Métodos e Técnicas e do Programa de Pós-Graduação em Educação da Faculdade de Educação da Universidade de Brasília. Líder do Grupo de Pesquisas Ábaco sobre o uso do computador na educação. Publicações recentes: Ensinar e aprender no meio virtual: rompendo paradigmas (Educação e Pesquisa, v. 37, p. 307-319, 2011); Uma pesquisa longitudinal sobre professores e computadores (Educação e Realidade, v. 36, p. 837-848, 2011). E-mail: glacerdađunb.br 